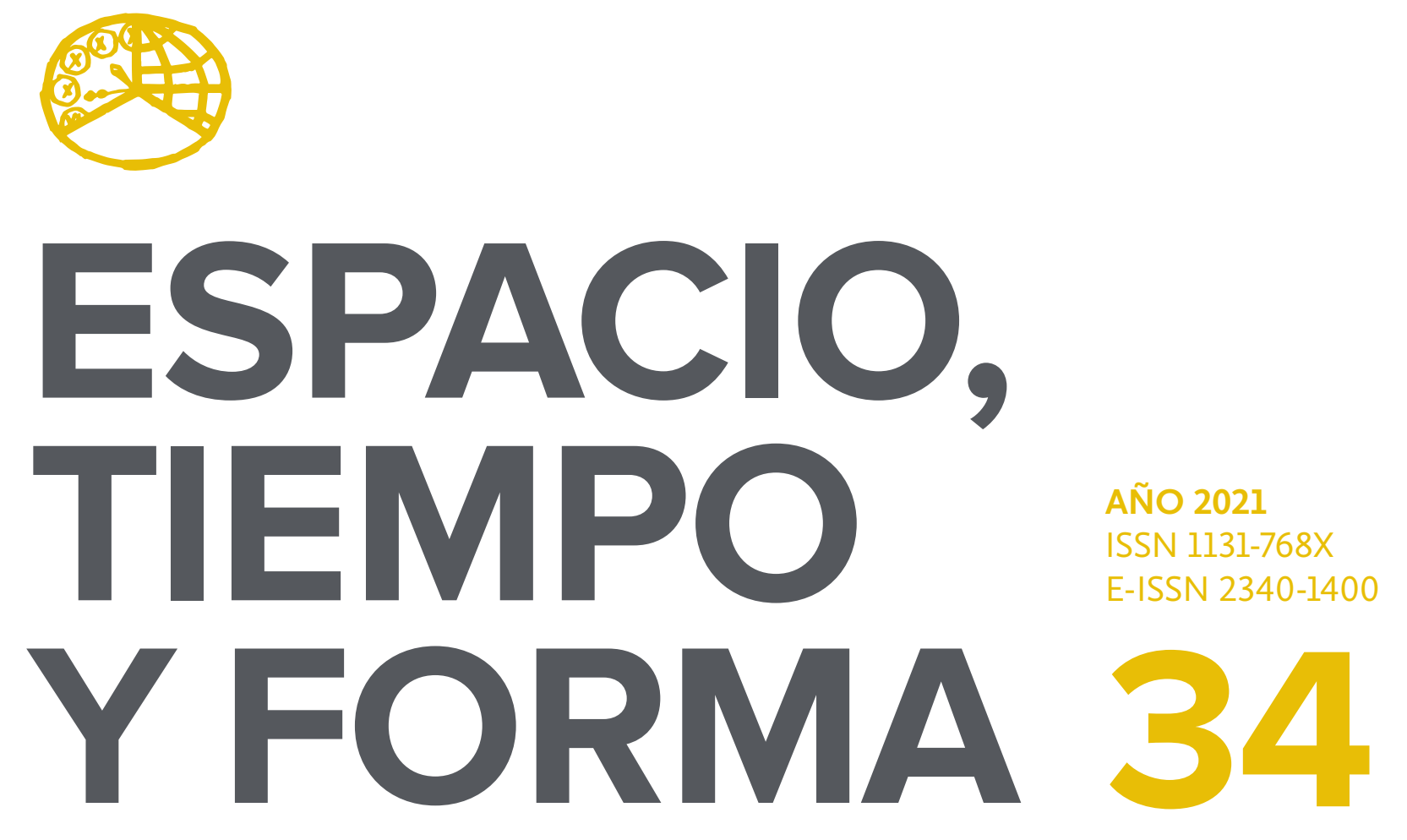

SERIE IV HISTORIA MODERNA

REVISTA DE LA FACULTAD DE GEOGRAFÍA E HISTORIA

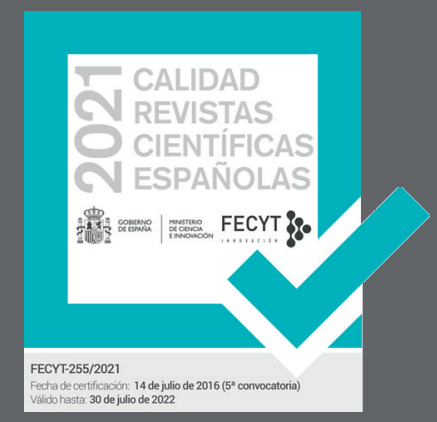




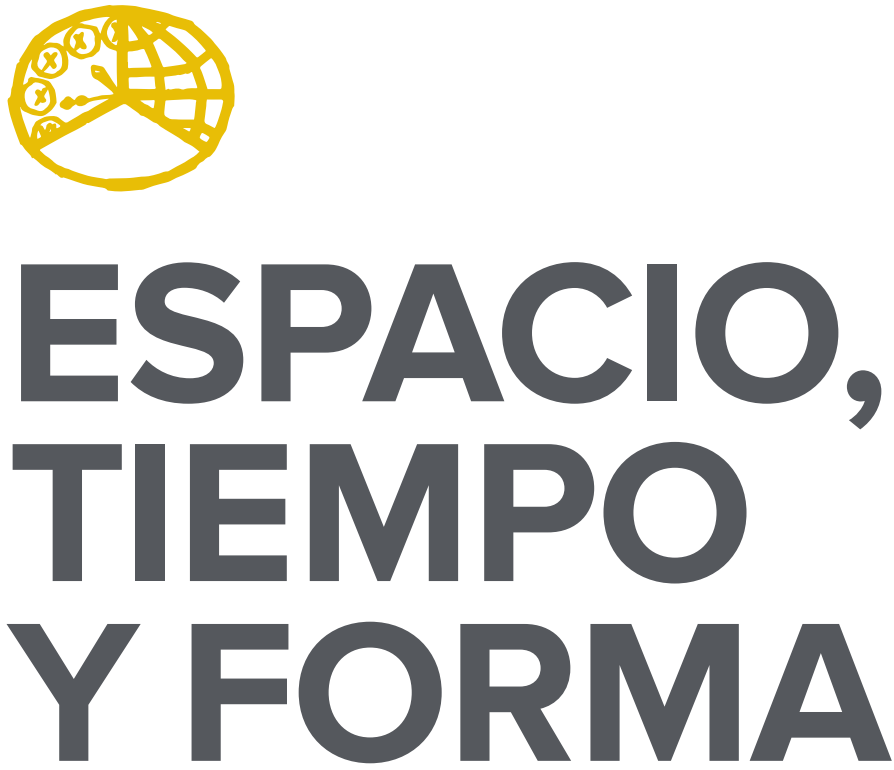

AÑO 2021

ISSN 1131-768X

E-ISSN 2340-1400

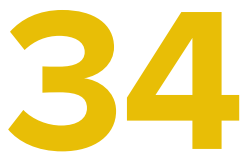

SERIE IV HISTORIA MODERNA

REVISTA DE LA FACULTAD DE GEOGRAFÍA E HISTORIA

DOI: https://doi.org/10.5944/etfiv.34.2021

\section{UกED}

UNIVERSIDAD NACIONAL DE EDUCACIÓN A DISTANCIA 
La revista Espacio, Tiempo y Forma (siglas recomendadas: ETF), de la Facultad de Geografía e Historia de la UNED, que inició su publicación el año 1988, está organizada de la siguiente forma:

$$
\begin{aligned}
& \text { SERIE I - Prehistoria y Arqueología } \\
& \text { SERIE II - Historia Antigua } \\
& \text { SERIE III - Historia Medieval } \\
& \text { SERIE IV - Historia Moderna } \\
& \text { SERIE V - Historia Contemporánea } \\
& \text { SERIE VI - Geografía } \\
& \text { SERIE VII - Historia del Arte }
\end{aligned}
$$

Excepcionalmente, algunos volúmenes del año 1988 atienden a la siguiente numeración:

$$
\begin{aligned}
& \mathrm{N} .^{\circ} 1 \text { - Historia Contemporánea } \\
& \mathrm{N}^{\circ} 2 \text { - Historia del Arte } \\
& \mathrm{N} .^{\circ} 3 \text { - Geografía } \\
& \mathrm{N} .^{\circ} 4 \text { - Historia Moderna }
\end{aligned}
$$

ETF no se solidariza necesariamente con las opiniones expresadas por los autores.

\author{
UNIVERSIDAD NACIONAL DE EDUCACIÓN A DISTANCIA \\ Madrid, 2021 \\ SERIE IV · HISTORIA MODERNA N. ${ }^{\circ} 34,2021$ \\ ISSN $1131-768 X \cdot$ E-ISSN 2340-1400 \\ DEPÓSITO LEGAL \\ M-21.037-1988 \\ URL \\ ETF IV · HISTORIA MODERNA · http://revistas.uned.es/index.php/ETFIV \\ DISEÑO Y COMPOSICIÓN \\ Carmen Chincoa Gallardo · http://www.laurisilva.net/cch \\ Impreso en España · Printed in Spain
}

(c) (7) (8) Esta obra está bajo una licencia Creative Commons Reconocimiento-NoComercial 4.0 Internacional. 


\section{MISCELÁNEA • MISCELLANY}





\title{
CONSTITUCIÓN INCREADA: FRANCISCO MARTÍNEZ MARINA Y LA CRÍTICA BÍBLICA
}

\section{UNCREATED CONSTITUTION. FRANCISCO MARTIINEZ MARINA AND BIBLICAL CRITICISM}

\author{
José María Iñurritegui Rodríguez \\ Recibido: 30/08/2021 - Aceptado: 05/10/2021 \\ DOI: https://doi.org/10.5944/etfiv.34.2021.31819
}

\section{Resumen}

El artículo propone la lectura de la Historia de la Vida de Jesucristo de Francisco Martínez Marina como ilustración de una economía cultural refractaria a toda forma de aplicación del ars critica a los textos bíblicos. Sugiere que la Historia permite visualizar que esa lógica de bloqueo no experimentó variación cuando una monarquía católica dio paso a una nación también católica. Y a su vez, posibilita reconocer que aunque en ese paso se sustanció un certamen entre quienes empuñaban la divisa clásica de la Monarchia in ecclesia y quienes auspiciaban un horizonte de religión civil, su debate fue intenso en materias referidas a la filosofía moral y política, pero estuvo lejos de erosionar el consenso básico en la defensa de la autoridad de las escrituras.

\section{Palabras clave}

Martínez Marina; Crítica bíblica; Nuevo Testamento; Nación católica; Constitución

\section{Abstract}

This paper proposes the reading of Francisco Martínez Marina's History of the Life of Jesus Christ as an illustration of a cultural economy refractory to any form of application of ars critica to biblical texts. It suggests that History makes it possible to visualise that this blocking logic did not change when a Catholic monarchy gave way to a Catholic nation. And, in turn, it makes it possible to recognise that although in this step a contest took place between those who wielded the classical motto of the Monarchia in ecclesia and those who sponsored a horizon of civil religion, its debate was intense in matters of moral and political philosophy, but it was far from eroding the basic consensus in the defence of the authority of the scriptures.

\footnotetext{
1. Universidad Nacional de Educación a Distancia; jinurritegui@geo.uned.es

Este trabajo forma parte del proyecto de investigación PGC2018-095007-B-loo financiado por el Ministerio de Ciencia e Innovación
} 


\section{Keywords}

Martínez Marina; Biblical Criticism; New Testament; Catholic Nation; Constitution 


\section{INTRODUCCIÓN}

Constitución increada es un sintagma derivado del entrecruzamiento de dos asertos contenidos en el cuerpo de la Historia de la Vida de nuestro señor Jesucristo publicada por Francisco Martínez Marina en Zaragoza en i832. El primero es la definición del evangelio como «código legislativo de los cristianos, que abraza la constitución del cristianismo y la vida de su divino autor», definición en la que Pablo Fernández Albaladejo detectó una de las hebras esenciales que posibilita encuadrar el pensamiento de Martínez Marina bajo el marbete de cristianismo cívico $^{2}$. Y el segundo es su paralela catalogación del propio evangelio como «saber increado» y por tanto estanco e indisponible para los agitadores de la «república de la opinión». Ambos asertos se realizan en el medio centenar largo de páginas que conforman el Discurso preliminar en el que procedía a una lógica y natural especificación del asunto, materia y método de la Historia ${ }^{3}$. Clarificaba que bajo ese título venía a publicar una «traducción literal al castellano» llamada a «poner en manos de los fieles los evangelios». Anunciaba también que aquel trabajo de traducción fijaba un «cuerpo completo de historia sagrada» depositario de unas «lecciones de sabiduría» cuya hondura moral excedía a todas las que habían «resonado en el pórtico y en las academias de Grecia y Roma» y a todas las custodiadas «en los archivos de la filosofía». Y tampoco dejaba de anotar que ese ejercicio de traducción resultaba altamente selectivo en el cuadro de los textos bíblicos y que respondía al entendimiento de «la excelencia, utilidad y ventajas de la nueva ley y del evangelio sobre la antigua», en cuanto depositario de un «código sagrado que contiene una revelación universal y el pacto solemne de Dios, no con un solo pueblo particular, sino con todas las naciones y pueblos de la tierra» ${ }^{4}$.

Eran cuestiones en las que se insistía y a las que recurrentemente retornaba, en una pieza que ha podido quedar ensombrecida por la propia trascendencia de otras de sus obras para el proceso de imaginación de una nación católica en el momento gaditano de $1812^{5}$. Pero lo que en este trabajo se plantea es que en ese mismo sentido ni la Historia ni su Discurso preliminar son insignificantes pues, por encima de la individualidad de cada uno de sus trazos, en aquellas páginas terminaba hilándose uno de los ensayos más sistemáticos de repudio de la crítica bíblica que desde hacía dos siglos había precipitado el cuestionamiento radical de la autoridad de las sagradas escrituras y su entendimiento como escrituras de autoridad. No se tratará por tanto de atender sólo y monográficamente a ese texto, sino ante todo de ubicarlo en el vocabulario con el que en la escena hispana se venía considerando desde algunas décadas antes la aplicación del ars crítica a la Biblia y la manera en la que a su vez su obra fija los términos de un legado que se transmite al liberalismo isabelino.

Para ello procederé en principio a situar los términos en los que la cultura católica hispana bloqueó cualquier forma de recepción de esa crítica sacra a lo

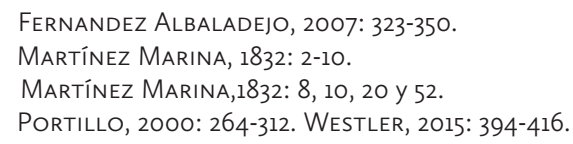


largo del setecientos, y de manera especial en el entorno de I782, momento en el que se restablece para el ámbito monárquico la posibilidad de la lectura y traducción de la Biblia al vernáculo. Para perfilar ese contexto me detendré en dos gestos que entiendo elocuentes: el primero, es la traducción en 1778 del texto de combate escrito por Jacques Benigne Bossuet contra Richard Simon, autor de la tentativa más cumplida y ambiciosa -al tiempo que fallida- de implantación de la crítica bíblica en el universo católico. El segundo, la comparecencia en I788 de un Diccionario de la santa biblia, debido a José Armesto y Goyanes, tan presto para plagiar la descripción del complejo mapa textual de las Sagradas Escrituras trazado por Mallet y Diderot en la voz «Bible» de la Encyclopédie como dispuesto a omitir el balance de progresos y tareas críticas pendientes que a continuación desgranaba. Asumo ambos gestos como definitorios en dos sentidos: por un lado, en cuanto fijación del vocabulario determinado por una exigencia absoluta de verdad histórica en el que se encauzó la deliberación sobre la traducción de las escrituras al vernáculo y al que se acogieron Scio de San Miguel (I790/93) y Félix Torres Amat (I823/25) en sus traducciones de la Biblia, el segundo de ellos con apropiación de la tarea previa del jesuita José Petisco; y, por otro, como ilustración de la distancia cultural que vino así a consolidarse frente al curso alternativo de imaginación de una Enlightenment Bible. Sobre esas coordenadas sugeriré la posibilidad de leer la Historia de Martínez Marina, y ante todo su Discurso preliminar, como un testimonio de la radicalidad con la que, incluso desde la complicidad con el cristianismo cívico y un horizonte de religión civil, podía asumirse como propia la preservación de la Biblia en un espacio intelectual inaccesible para la crítica. Y así, finalmente, plantearé una doble conclusión: en primer lugar, que el encastillamiento frente a la reescritura del mito cristiano no experimentó ninguna variación cuando una monarquía católica dio paso a una nación también católica ${ }^{6}$; y en segundo lugar, que aunque en ese paso se sustanció un certamen entre quienes empuñaban la divisa clásica de la Monarchia in ecclesia y quienes auspiciaban y anhelaban un horizonte de religión civil, su debate fue intenso en materias referidas a la filosofía moral y política, pero estuvo lejos de erosionar el consenso básico en la defensa de la autoridad de las escrituras.

2.- Las aguas de la erudición dedicada en sentido estricto a la palabra de Dios bajaban agitadas en la segunda mitad del XVII7. Todos los supuestos tradicionalmente aceptados sobre la coherencia de las sagradas escrituras, y que afectaban a motivos de autoría, pero también de geografía y cronología, estaban siendo desestabilizados entonces de manera además radical ${ }^{8}$. Incluso la propia sacralidad del texto bíblico, que en sí misma resultaba cuestionada, había dejado de constituir para algunas figuras ilustres de la república de las letras una prueba y justificación suficiente de su veracidad. Ese era el complejo y convulso panorama de la alta crítica bíblica ante el que el sacerdote oratoriano Simon había venido a posicionarse con sus Histoires

6. El entendimiento del proceso como reescritura del mito cristiano en Laplanche, 1994: 33 y ss. Y para su comprensión en un horizonte donde no dejaban de concurrir otras mitologías igualmente acríticas, Grossi, 2001.

7. HARDY, 2017. BERNIER, 2010.

8. Rossi, 2003. 
critiques, primero con la del Vieux Testament, en I678, y luego con la del Nouveau, en I6909. Afamado hebraísta, Simon escribía ante todo para dar continuidad y profundizar con su particular erudición en algunas líneas de fractura críticas ya previamente perfiladas: entre ellas, el cuestionamiento de la autoría mosaica del Pentateuco, la comprensión de la Biblia como un conjunto contradictorio, alterado y viciado por la historicidad, o la necesidad de comprenderla como una construcción histórica cuya plena comprensión dependía de su lectura en conjunción con otras historias antiguas. Pero también escribía para tomar y fijar distancias frente a otras vías entonces abiertas, como pudiera ser la sentencia de Spinoza de que las sagradas escrituras estaban escritas por humanos y para humanos, que la Biblia hebrea había sido tardía en su composición y particular en su enfoque, en cuanto compilada por el sumo sacerdote Esdras para confirmar la obediencia de los hebreos a la Ley de Moisés tras su cautiverio en Babilonia ${ }^{\text {io }}$. A diferencia no obstante de todos quienes le habían precedido, ese delicado y sutil juego de complicidades y desencuentros se disponía y desplegaba en las Histoires crtiques con una intencionalidad radicalmente novedosa: deslegitimar el principio confesional de la sola scriptura. En manos de Simon, la fragilidad evidenciada por las sagradas escrituras ante la inquisitiva pericia crítica devenía en una reivindicación de la centralidad de la tradición, y con ello de la Iglesia que enraizada en esa tradición se proyectaba como la única instancia legitimada y capacitada para imponer una regla de fe que la Biblia por sí misma no podía establecer.

Frente a las mentes ortodoxas que vislumbraban en aquella hermenéutica la apertura de la senda hacia el panteísmo y el ateísmo, Simon estaba convirtiendo las incertidumbres de los textos de las sagradas escrituras, que tanto contribuía a identificar, en la evidencia suprema de la necesidad del juicio y por tanto la autoridad de la Iglesia. Las Histoires critiques se concebían en ese sentido como una tentativa de encauzar en clave católica la energía liberada por la crítica bíblica ${ }^{\text {II }}$. Pero la inmediata secuencia conformada por la expulsión de Simon de la congregación del oratorio, el secuestro de la primera edición de la Histoire du Vieux Testament a instancia de Bossuet, y la inclusión de la obra en el Index de I682, vino a anunciar que ese género particular de erudición que era la alta crítica bíblica había de tener en latitudes católicas una suerte radicalmente distinta a la fortuna de la erudición maurista de Jean Mabillon ${ }^{12}$. La desconfianza ortodoxa hacia la específica forma de relación y composición entre la crítica y la autoridad que propugnaba Simon no haría además sino acentuarse. En especial cuando su audacia epistemológica se aplicaba en la Histoire critique des commentaires du Nouveau Testament, publicada en I693, a la tarea de discriminación y detección de unas «veritables traditions de 1’ Eglise» ${ }^{\text {r3 }}$.

9. GUSDORF, 1988: 109-121. TWINING, 2018: 421-487. KOSELLECK, 2007, 98-99, interesando además esta última referencia en su conjunto para incardinar la crítica sacra en la interacción mayor entre crítica y crisis.

10. MALCOLM, 2002: 383-430. JMORROW, 2016: 104-138. POPKIN, 1986: 383-407.

11. Momigliano, 1990: 73.

12. LAMBE, 1985: 149-177.

13. BERNIER, 2008: 199-223. 
Su tesis era sencilla, e incluso evidente: derribar el principio de la sola escritura no sólo obligaba a la depuración textual de la Biblia, sino también a sustituir el entendimiento monolítico de una tradición por el de una pluralidad de tradiciones, y a filtrar las mismas con el utillaje de la crítica para fijar las susceptibles de ser definidas y asumidas como veritables. Afirmar que el componente humano de todas las tradiciones requería afrontar el problema de la fidelidad de su trasmisión y de su legitimidad, aunque en ello se comprometiera el legado teológico de figuras como la de San Agustín, era así, en la exposición de Simon, el cierre del círculo abierto al apuntar la insuficiencia del texto bíblico para soportar por sí mismo los dogmas de la fe. Embarcado desde un principio en su implacable persecución, receloso en primera instancia de que el aggiornamiento crítico de Simon abriese la senda del control de la hermeneútica bíblica a una instancia soberana de signo hobbesiano, o en su defecto a un rearme del poder papal, Bossuet leyó sin embargo la tesis de esa Histoire critique des commentaires du Nouveau Testament de forma bien distinta a la propuesta por su autor ${ }^{14}$. Interpretó, sin el menor atisbo de duda, que Simon había articulado un artificio retórico, en nombre de la exégesis y la ciencia textual, que abocaba al «abismo de la incertidumbre», pues «por el mismo medio por el cual primero ha debilitado las pruebas de la escritura como defensa de la tradición, igualmente destruye luego las que se pueden deducir de la tradición». Entendió así que había llegado el momento de formalizar una réplica más sistemática a las obras de Simon: «No es justo abandonar más largo tiempo a los críticos modernos la doctrina de los Padres y tradición de la Iglesia». De ajustar cuentas con su erudición y condición de «crítico», que apegado a las «reglas de gramática» procedía a «decidir sobre la fe y la teología por el griego o por el hebreo». Bossuet asumía con clarividencia que el reto planteado por Simon era doble: por un lado, por su misma condición católica; pero también, y de forma particular, porque aunque autores como Hobbes y Spinoza habían planteado auténticos puntos de crítica sobre la historicidad y la textualidad de las escrituras no lo habían hecho de una forma tan profunda y erudita como Simon, que por ello requería una refutación detallada y no sólo el anatema de la impiedad. Bossuet se aplicó así durante la última década de su vida a la redacción de una completa Défense de la Tradition et des Saints Pères que sólo se publicaría de forma póstuma. Y aquella Defense, centrada en revestir a Simon con los ropajes teológicos del arrianismo y el socinianismo, comparecía en traducción castellana en $1778^{15}$.

Esa traducción puede ser analizada como un capítulo más del proceso de recepción profunda de Bossuet a lo largo del Setecientos hispano, cuando se traducen sistemáticamente y reeditan con suma frecuencia todas y cada una de sus obras mayores. Pero también puede serle atribuida una singularidad más acentuada: la de ser la única pieza del debate abierto por el criticismo bíblico que alcanzaría en todo ese tiempo traducción al castellano. En un orden cultural en el que no hay atisbo alguno de recepción de Simon, ni siquiera en los círculos como el que gravita

14. LE BRUN, 2012: 257-273.

15. BOSSUET, 1778a. 
alrededor de Mayans que con tanta determinación asumen la cruzada de la erudición maurista, la iniciativa de traducir la Defensa no era además ninguna ocurrencia de su traductor. El mismo 1778 en que José Cabezas la llevaba a la imprenta también se reeditaba la traducción del Discurso sobre la historia universal del propio Bossuet ${ }^{16}$, cuya subordinación de la historia secular a la historia eclesiástica, que remite al modelo forjado por Eusebio de Cesarea, Paulo Orosius u Otto de Freisinga, formalizaba su respuesta frente a quienes venían revisando radicalmente la comprensión de la historia sagrada como matriz de la historia universal. La narrativa histórica que a la altura de 1778 se había ido abriendo paso de la mano de Giannone, Hume o Voltaire hasta culminar en Gibbon, y que procedía a separar la historia de Europa de la historia de la cristiandad, resultaba al fin y al cabo indisociable de las lecturas que como la de Jean Le Clerc, bien distinta a la de Bossuet, también había motivado el estudio de los textos bíblicos a través del lenguaje y la contextualización ${ }^{17}$.

Le Clerc entablaría su particular debate con Simon, cuestionando su afirmación de que los libros vetero-testamentarios habían sido compuestos por escribas públicos que trabajaban bajo la dirección de Moisés y los Profetas, y que por tanto estaban inspirados y contaban con la autoridad de Dios. Con una paralela adopción de la teoría del conocimiento de John Locke, a quien también interesaba el planteamiento de Simon, su opción sería establecer cuándo y quiénes escribieron aquellos libros, estimulando un proceso de sustitución de la teología por una historia del lenguaj $\mathrm{e}^{\mathrm{r}}$. Conceptualizable como illuminismo di Dio, esa conversión de la teología en su historia como construcción humana, conducida por historiadores de la Iglesia, discurriría en paralelo a los debates sobre la sociabilidad y los orígenes de la sociedad civil $^{19}$. Pero no precisamente en las coordenadas de la economía cultural de una monarquía católica tan afecta a Bossuet como desafecta a Simon.

Il.- La historia de la traducción bíblica al castellano se adentraba en una nueva dimensión justo inmediatamente después, en I782, cuando tras el paréntesis de más de dos siglos el tribunal inquisitorial hispano restablecía la licitud de su lectura y traducción al vernáculo ${ }^{20}$. Y en 1790 comparecían los primeros volúmenes de $L a$ biblia vulgata traducida en español del escolapio Felipe Scio de San Miguel, preceptor de los infantes ${ }^{21}$. Como acreditaba la misma, esa dimensión entonces abierta no se proyectaba exenta de demarcaciones. El propio decreto firmado en I782 por el inquisidor general Felipe Beltrán encerraba ya una singularidad: la de su fecha, tardía al menos a la luz del cuarto de siglo discurrido desde que el papa Benedicto XIV había modificado la regla IV del índice tridentino autorizando nuevamente a los autores católicos la traducción de la biblia. Era un retraso que, con tanta delicadeza

\footnotetext{
16. BOSSUET, $1778 \mathrm{~b}$.

17. PoCOCK, 2010: 89-114.

18. PITASSI, 1987.

19. BORDOLI, 2004. POCOCK, 2008.

20. Para los pormenores y la contextualización de esa secuencia, MESTRE, 1987: 181-236; EGIDO, 1996: $739-814$. SÁNCHEZ CARO, 2012.

21. La Biblia Vulgata latina traducida en español y anotada conforme al sentido de los Santos Padres y expositores católicos por Phelippe Scio de San Miguel, Valencia, Oficina de Joseph y Thomas de Orga, 1790-93.
} 
como firmeza, ya había venido a problematizar Diego González al prologar en I779 su edición de la Exposición del libro de Job de Fray Luis de León, incorporando para ello la trascripción íntegra del breve de Pio VI a Antonio Martini, futuro arzobispo de Florencia, en el que celebraba su traducción de la Biblia al italiano ${ }^{22}$.

En ese contexto deliberativo, que antecede al pronunciamiento de Beltrán, la traducción de la Defense de Bossuet adquiría pleno sentido. Particularmente porque enlazaba con la lógica de una doble limitación acotada en el decreto pontificio y que la norma inquisitorial hispana reproduciría fielmente: la que imponía que las traducciones a las que ahora se abría la iglesia católica habían de operar obligadamente con la vulgata como texto de partida y contar con la autorización papal, o estar «impresas con anotaciones de los Santos Padres o de autores católicos y doctos». El tiempo nuevo que para la traducción bíblica venía a inaugurarse ni conllevaba por tanto la cancelación del monopolio hermenéutico que se arrogaba una iglesia, ni otorgaba al traductor ninguna jurisdicción sobre la traducción, ni abría la posibilidad de que la lectura individual del antiguo y del nuevo testamento se convirtiese en una experiencia directa, no intermediada por intérpretes canonizados por la tradición. Así las cosas, al presentar su texto Scio lo hacía anunciando desde la titulación que su «Biblia vulgata latina traducida en español» estaba oportunamente «anotada conforme al sentido de los Santos Padres y expositores católicos» y que su aspiración había sido así la de la invisibilidad como traductor.

A esas demarcaciones se sumaban por lo demás unos recelos. La iniciativa de Scio, pese a la complicidad de Carlos IV, no era culturalmente descomprometida. Antes de su publicación, la mera noticia de su proceso de elaboración suscitaba una desconfianza a la que daba forma el primero de los volúmenes del Diccionario histórico, cronológico, geográfico y universal de la Santa Biblia de José Armesto y Goyanes en I788. Dispuesto en cuatro volúmenes publicados entre I788 y I792, el Diccionario decía hacerse cargo para la Biblia de una tarea paralela y coherente con la emprendida algo antes por Esteban Terreros y Pando en su Diccionario para las artes y las ciencias: la de modelar un vocabulario, del que así se reconocía su carencia, con el que conducir la tarea de traducción al castellano ${ }^{23}$. Ambos Diccionarios parecían así situarse en idéntica posición, con la lengua como problema. Pero la sintonía podía ser engañosa. Terreros había imaginado y emprendido la confección de su Diccionario al constatar en su desempeño como traductor, y ante todo en el trance de traducción del Espectáculo de la Naturaleza de Pluche, la insuficiencia del castellano para conducir con propiedad ese empeño. Se trataba así de habilitar una lengua de llegada para las operaciones de traducción. Armesto levantaba sin embargo su vocabulario bíblico no sólo, ni esencialmente, como instrumento de capacitación lingüística sino también, y ante todo, como tentativa de delimitación cultural del lenguaje con el que habían de conducirse quienes, como Scio, aspiraban a adentrarse en el ámbito de la traducción bíblica entonces reabierto.

22. Fray Luis de LeÓN: 1779: Prólogo.

23. Armesto y Goyanes, 1788: I, Prólogo. Terreros y Pando, 1786. 
El Diccionario articulaba toda una defensa de la tradición y la vulgata. Abría ya su prólogo con una doble precisión al respecto: primero, sentenciando que el único medio para descifrar el «complejo de verdades puras pero misteriosas» de los «libros sagrados» era la «doctrina de los Intérpretes y Santos Padres» y no en «el entendimiento y la erudición humana». Y a continuación, figurando la Vulgata como la fijación textual que resolvía cualquier duda sobre «los conductos por donde tan misterioso libro ha llegado a nuestras manos», y también cualquier sombra e «incertidumbre de su buena traducción a la lengua latina, o falta de expresión correspondiente a la de su original». Huir de la veleidad «crítica» devenía así en el primero de una serie de mandamientos antes de traducción que de lectura cuya disposición se encaminaba a resaltar «el inconveniente que se sigue de la traducción de los libros sagrados a nuestro idioma, ya sea la versión parafrástica, ya literal, si se toman por original la de otras naciones». Su conclusión sin embargo distaba mucho de circunscribirse a la mera tarea de «inferir que para la versión de la Biblia en castellano ha de servir de texto original la hebrea, o Vulgata, con las notas correspondientes según lo prevenido por decreto del Santo Oficio». Dando un paso al frente, Armesto sentía la necesidad de evitar que cayesen en el olvido «los motivos y razones que tuvieron nuestros mayores para no permitir las traducciones al vernáculo». Es más, era tanta su adhesión a las mismas que incluso se veía obligado a precisar que «no por esto censuramos las traducciones de los libros sagrados que se van ideando en estos tiempos». Pero a su vez era esa indisimulada desconfianza hacia la traducción la que le inducía a componer un Diccionario que no se limitaba a «poner a la vista los varios significados que tienen las palabras», sino que procedía a incorporar «una noticia competente de la historia sagrada», algunas «reflexiones morales» y una serie de «noticias cronológicas y geográficas» llamadas a sellar cualquier posible vía o resquicio de recepción de la reescritura del mito cristiano conducida por el progreso de la crítica bíblica.

El rigorismo teológico del artefacto textual y cultural que así modelaba Armesto quedaba retratado en su determinación de abandonar la que había sido su estrategia inicial y que, según se dejaba puntual constancia, pasaba antes que por la composición por la traducción «de algún Diccionario de los que hay impresos en otros idiomas». Sin lugar, como es de suponer, para imaginar siquiera la adopción del Dictionnaire de la Bible (Lyon, Jean Certe, I703) de Richard Simon, Armesto confesaba que la primera opción barajada había sido la de verter al castellano los 26 volúmenes del Dictionnaire historique, critique, chronologique, géographique et littéral de la Bible publicados entre I707 y I7I6 por Agustim Calmet. A la hora de decantarse entre Bosuet y Simon, la filias y las fobias de Armesto estaban claras. Con Calmet sin embargo el terreno de la hermenéutica bíblica se antojaba más resbaladizo. Tanto como para terminar suscitando un verdadero proceso de enjuiciamiento en el que los cargos interpuestos contra él, comenzando por lo «impropio de su inmensa erudición profana», decían sin duda más de Armesto que del propio autor del Dicctionaire. En I789, un año después de la publicación del Diccionario, podía dispensarse una mirada bien distinta a Calmet y concretarse la traducción de su Historia del Antiguo 
$y$ nuevo Testamento ${ }^{24}$. Armesto sin embargo no albergaba ninguna duda sobre lo que en verdad se dilucidaba en aquellas decisiones de traducción. Lo evidenciaba, y con ello su capacidad para dispensar una lectura profunda de la obra de Calmet, al justificar su decisión de abandonar la idea de su traducción alegando que «podría ser arriesgada la traducción de muchos puntos de crítica y controversia que contiene aquel Diccionario, careciendo por otra parte de reflexiones morales». La voz «Biblia» abrochaba luego ese planteamiento. Estaba literalmente tomada en sus primeros parágrafos de la voz Bible redactada por Edme-François Mallet en colaboración con Diderot para la Encyclopedie, los dedicados a describir la composición de la Biblia como conjunto de libros y a repasar sus traducciones. Pero en el Diccionario desaparecían por completo las precisiones de subido valor que a continuación dedicaban Mallet y Diderot a trazar el balance de los logros asentados por la crítica y la relación de tareas aún pendientes en ese terreno ${ }^{25}$.

4.- Scio, de cuya iniciativa y avances estaba al corriente Armesto, se ajustaría plenamente a esas demarcaciones inquisitoriales reforzadas por el Diccionario y a esa negación del programa de Diderot. Pero ello distó mucho de garantizarle una acogida pacífica para su traducción. Al revés. La principal prueba del enrarecido ambiente que contextualizó su aparición sería la Advertencia que el propio Scio sintió la necesidad de incorporar a la segunda edición de su traducción, que salía de las prensas de Benito Cano en Madrid en I794, se iniciaba por el Génesis y no por el Nuevo Testamento como la primera y en la que ya no se incluía la edición de la vulgata latina. Esa Advertencia se disponía elocuentemente con un tono reivindicativo como una sistemática acumulación de referencias a las diferentes y autorizadas instancias que desde su primera redacción habían testado la ortodoxia de la traducción hasta llegar a la imprenta, y las que a continuación, una vez ya publicada, habían tutelado la revisión de las novedades que incorporaba ahora aquella segunda edición. Al igual que ocurría con el detallado enunciado del encargo recibido para emprender su tarea de parte de Carlos III a través del secretario de estado Manuel de Roda en I780, antes por tanto de concretarse el pronunciamiento inquisitorial hispano, Scio poblaba la Advertencia con unos apuntes sobre el riguroso umbral censorio superado por el texto cuya anotación no había entendido necesaria en su inicial presentación y que filtraban una lúcida conciencia sobre la notable desconfianza suscitada no por su traducción, sino por la traducción de la Biblia ${ }^{26}$.

No era éste ciertamente un flanco que el escolapio hubiera desatendido en la edición de I79o. En el Discurso preliminar de su traducción lo abordaba Scio en un doble sentido. Por un lado, dando continuidad al argumento de que la traducción bíblica era una estrategia natural en la iglesia y el cristianismo primitivo sobre el que en esos años venían incidiendo piezas como la traducción al castellano en I789

24. CALMET, 1789

25. Armesto y Goyanes, 1788: 172-18. Mallet y Diderot, 1751: 2, 222-227.

26. La Biblia Vulgata latina traducida en español y anotada conforme al sentido de los Santos Padres y expositores católicos por Phelippe Scio de San Miguel, revista, corregida y aumentada por su mismo traductor, Madrid, Imprenta de Don Benito Cano, 1794: xii-xx. 
por José Palacio y Viana -a partir de la versión de Antonio Pereira de Figueiredodel Apocalipsis de San Juan. Y por otro, procediendo a la fijación de una específica memoria de nación, la memoria de una nación que había practicado la traducción de los libros bíblicos «desde la formación de nuestra lengua castellana» y que albergaba hitos mayores como el de la primera biblia europea en romance, debida a Alfonso X el Sabio. Interesaba sin embargo más en aquellas páginas consignar el desafío que suponía afrontar la traducción con la rémora de una lengua carente de la debida estabilidad, por mucho que ello no impidiera confiar plenamente en el «augusto carácter y la propiedad de nuestra lengua para trasladarse a ella los oráculos del Espíritu Santo ${ }^{27}$. Todo el argumento en favor de la traducción literal frente a la opción perifrástica que a continuación se desgranaba, y que encerraba una cautela teológica evidente, pendía de esa dimensión lingüística primaria. Y en todo ello se insistía al reeditarse la obra en I794, incluso con un desarrollo más cumplido y revelador de la particular posición desde la que operaba como traductor. Pero acompañado ahora de ese combativo nudo argumental que parecía requerirse para disipar las dudas sobre la licitud misma de la traducción al vernáculo, por mucho que hubiera un pronunciamiento del poder inquisitorial al respecto.

Esa pulsión latente que problematizaba y condicionaba el vertido de la Biblia al vernáculo dejaría su huella impresa en diversos textos del tiempo, comenzando por los que entonces concurrieron en defensa de la empresa traslaticia. Aunque buena parte de su forma de razonar hubiera estado anticipada ya en piezas como el prólogo de Palacios y Viana a su traducción del Apocalipsis de San Juan, o en el de Anselmo Petite a la suya -de I785- de Los Santos Evangelios, ninguno quizás fue más sistemático y contundente en ese sentido que el publicado en I79I por Joaquín Lorenzo de Villanueva. Su De la lección de las sagradas escrituras en lenguas vulgares se escribía con pretensiones bien definidas: instruir a «ignorantes» que como «nunca habían visto los libros sagrados en manos del pueblo» creían «que en esto no cabía variedad»; estimular a quienes, «no tan ignorantes, pero tímidos, decían que no estábamos aún en estado» de retomar la traducción bíblica; y, muy especialmente, rebatir y desautorizar a ciertos teólogos que «por cierto respeto a los misterios y arcanos de la sagrada escritura, dijeron que no era bien ponerlos en las manos del vulgo, que al pueblo bastaba enseñarle lo necesario para salvarse». Contra ellos no sólo reiteraba Villanueva que la Biblia, originalmente escrita en hebrero y vertida luego al griego y al latín, también había tenido una larga historia de traducción al vernáculo, y en concreto al castellano. Interponía además un argumento, perfilado antes por Petite ${ }^{28}$, que Scio retomaría con vigor en la segunda edición de su obra: el entendimiento de que la prohibición que había pesado sobre la traducción al vernáculo en el ámbito católico, contrariamente a lo que habían escrito Bellarmino o Alfonso de Castro, no era una cuestión de «dogma» sino de

27. La Biblia Vulgata latina traducida en español..., 1790: I, Dedicatoria «Al Rey Nuestro Señor Don carlos IV》 y xvi; Apocalypsis del Apostol San Juan traducido al castellano según la Vulgata con las anotaciones históricas, dogmáticas y morales que trae en su versión Don Antonio Pereira de Figueiredo, Diputado en Lisboa de la Real Mesa Censoria, por D. José de Palacio y Viana, Madrid, Isidoro Hernández Pacheco, 1789: Prólogo.

28. Petite, 1785 -que cito por la edición de Madrid, Imprenta Real, 1788-: Prólogo, vii. 
«disciplina», y que por tanto obedecía a un ejercicio prudencial sujeto a la exégesis de «las circunstancias, los lugares y los tiempos $»^{29}$. Y un cuarto de siglo después, en I823, cuando sirviéndose de los trabajos previos del jesuita José Petisco cerraba una nueva traducción del texto bíblico, Félix Torres Amat se podía mostrar no menos rotundo al retratar el momento de la traducción de Scio como un tiempo condicionado por la resistencia «fanática» frente al desdoblamiento al vernáculo ${ }^{30}$. La estricta adhesión a la estrategia de la literalidad por parte de Scio constituía en realidad, para Torres Amat, un retrato diáfano de aquel tiempo, pues la entendía como una estrategia traslaticia que obedecía antes a motivos contextuales que al propio convencimiento del escolapio.

Esa referencia de Torres Amat al método traslaticio podía entrañar cierta deformación y no ser del todo inocente. En las Advertencias a su traducción de los evangelios, Petite se mostraba como un firme partidario de guiarse por el Ad Pammachium de optimo genere interprtandi de San Jerónimo, y así, tratándose del «texto sagrado», "preferir religiosamente la sujeción a la letra a la fluidez y elegancia de estilo, y estimar más la cualidad de fiel traductor que la de retórico elocuente» ${ }^{3 \mathrm{I}}$. Y nada en la presentación de Scio induce a pensar en que le incomodase su adhesión a la literalidad - $a d$ verbum-32. Pero Amat podía encontrar ahí una forma de ensalzar la pertinencia y las bondades de su traducción, porque en ese plano su opción era diferente a la de Scio. Entendía que en sus días cabía traducirse con «una justa libertad», sin caer en todo caso en la «paráfrasis», y evitando siempre el «escollo de afectar un género de elegancia profana» ${ }^{33}$. Sin renunciar a ensalzar la obra de Scio y erigirse en su heredero, podía también reservar a Martini el lugar más honorable de su particular altar de traductores. En lo que sin embargo no se separaba ni tan siquiera un ápice de Scio, o del Villanueva que lo respaldaba, era en la causa que los movilizaba al embarcarse en la traducción bíblica y en la determinación del principal de los efectos morales, sociales y políticos que aspiraban a propiciar: regenerar las costumbres. Ambas traducciones, apegadas a la Vulgata y despojadas de cualquier atisbo de criticismo, al igual que Petite, Villanueva o Palacio y Viana, ensalzaban las escrituras como el verdadero antídoto para revertir lo que retrataban como un proceso de corrupción de las costumbres ${ }^{34}$. Abrían por tanto un cauce paralelo al de quienes a partir de un diagnóstico similar sobre ese proceso de corrupción miraban hacia saberes novedosos, como el de la economía política, en busca de una dimensión de futuro 35 .

29. VillanueVA, 1791: Prólogo y pp. 59-60 y 106-126. La Biblia Vulgata latina traducida en español...revista, corregida y aumentada..., 1794: I, xii y xxvi-xxxix.

30. La Sagrada Biblia nuevamente traducida de la Vulgata latina al español, aclarado el sentido de algunos lugares con la luz que dan los textos originales hebreo y griego, e ilustrada con varias notas sacadas de los Santos Padres y expositores sagrados, por Félix Torres Amat, Madrid, Imprenta de Don Amarita, 1825: I, Prólogo.

31. Petite, 1785: xi-xiv.

32. Ni en la primera edición -La Biblia Vulgata latina traducida en español..., 1790: I, xxvii-xxxi- ni en la segunda: La Biblia Vulgata latina traducida en español... revista, corregida y aumentada..., 1794: I, Ixiii-Ixxvi y ci-ciii.

33. La Sagrada Biblia nuevamente traducida de la Vulgata latina al español..., 1823: I, Prólogo, i-iii.

34. La Biblia Vulgata latina traducida en español..., 1790: I, ii-vi y xxxi; La Biblia Vulgata latina traducida en español..., 1794: I, cX-cxxiii.

35. SÁNCHEZ LEÓN, 2005. 
Asentar que la circulación en vernáculo de la Biblia no era «causa de herejía» atendía, en ese sentido, a un preciso frente de conflicto primario. El previo a la batalla que aspiraba a darse: la de desactivar los cantos de sirena de un «tolerantismo» que, estimulado en «libros de gente libertina», actuaba como disolvente «de los lazos que tiene el hombre con Dios y con las potestades legítimas» ${ }^{36}$. En I790 y en I823, de lo que así se trataba era de liberar mediante la traducción bíblica un potencial de modulación del funcionamiento de la sociedad y de la conducta humana al que su enclaustramiento en el latín amenazaba con privar de operatividad. En palabras de Villanueva, plenamente acordes con la forma de razonar del Catecismo de estado (Madrid, I793) que publicaba casi al tiempo que su De la lectura, la traducción de la Biblia se vislumbraba como la llave maestra para recomponer, bajo el signo ahora de la «pública felicidad», el quebrado engranaje entre las «buenas costumbres, la simplicidad evangélica, la sana política y la subordinación a las potestades» ${ }^{37}$. Convenía por ello evitar equívocos y recordar, como recordaba Torres Amat, que los libros bíblicos «los dictó Dios, no para enseñar a los hombres la ciencia, sino lo perteneciente a la fe y las buenas costumbres». Ese era el caso y el asunto. Y el propio Amat lo concretaría aún con más plasticidad. Lo que la traducción había de conjurar era la posibilidad misma de que pudiera llegarse a «mirar los libros sagrados como los escritos de Homero, los de Ossian y de otros autores profanos» ${ }^{38}$.

5.- En I788, el mismo año en el que Armesto y Goyanes inicia la publicación del Diccionario, José Alonso Ortiz -traductor luego de Adam Smith- llevaba a la imprenta el primero y único volumen que traduciría de las Obras de Ossian, poeta del siglo tercero en las montañas de Escocia, los poemas inventados por James Macpherson en los que un bardo celta cantaba la constitución libertaria de las tierras de Fingalia y que Torres Amat situaba en su comentario flanqueando a la figura de Homero y con distinción respecto a la abstracta alusión a otros autores profanos. Aquella utopía de las tierras altas celtas, en las que la solidaridad republicana demostraba ser compatible con los modales más civilizados, tendría una notable presencia y resonancia en la ilustración europea, y sus ecos en las letras hispanas tampoco serían efímeros: a la traducción de Alonso Ortíz le seguía en i8oo una nueva, Fingalia y Tamora, poemas épicos de Ossian, de la mano de Pedro de Montegón. La más honda sustancia y lección política que portaban esos poemas, la identificación de las manners como elemento compensatorio de la pérdida con el progreso comercial de la virtud antigua de aquellos guerreros celtas celosos de su independencia y autosuficiencia, no guardaba relación directa con el universo y el lenguaje poético de Homero 39 . Pero lo que parecía inquietar a Torres Amat y le inducía a reunirlos en su comentario no era exactamente una cuestión de sustancia y enseñanza política, sino el peligro de que la manera en la que aquellas poéticas se abrían y adoptaban

\footnotetext{
36. La Biblia Vulgata latina traducida en español..., 1790: I, iii.

37. VILLANUeVA, 1791: Dedicatoria al Conde de Floridablanca.

38. La Sagrada Biblia nuevamente traducida de la Vulgata latina al español..., 1823: I, Prólogo, vi.

39. POTKAY, 1992: 120-30.
} 
como una ventana de contemplación de civilizaciones pasadas pudiera hacerse extensiva a la lectura de la Biblia $^{40}$.

Superado el particular momento hispano en el que era altamente polémico afirmar que la traducción bíblica al castellano se había primero detenido y luego retomado, al igual que en el resto del mundo católico, por una cuestión de tiempo y circunstancias, el verdadero eje de debate se situaba así en los modos y presupuestos de lectura y comprensión de la Biblia a los que servía la traducción. Se hacía notar en ello el que, a esas alturas, y en ciertos espacios de implicación confesional reformada de la republica de las letras europea, ya se hubiera asistido al alumbramiento de The Enlíghtenment Bible, la metamorfosis de la Biblia desde su condición como libro sobre Dios y escritura de autoridad a su entendimiento como un libro sobre la humanidad despojado de cualquier dogma teológico ${ }^{41}$. Capítulo crucial en la historia -por decirlo con un título de Michael C. Legaspi ${ }^{42}$ - de «the death of scripture and the rise of biblical studies»-, alentados por los avances en el scholarship filológico, literario e histórico, el principal estímulo que movilizaba a los artesanos de aquella Enlightenment Bible no se enfocaba en fijar mediante la traducción un artefacto que mantuviese bajo férreo control teológico la autoridad de las escrituras sino otro, cultural, cuya autoridad se distribuyera en diversos ámbitos disciplinarios. Justamente, la vocación contraria a la que guiaba a Scio de San Miguel o a Torres Amat. No era casual ni resulta anecdótico que mientras Michaelis estaba diseñando como parte de su proyecto de traducción una ambiciosa expedición al corazón de Arabia que buscaba manuscritos, costumbres culturales, los nombres de la flora y la fauna y cualquier otra información que pudiera impartir la comprensión de la Biblia, Scio estuviera centrado en dar cuerpo a una retícula de comentarios patrísticos para su traducción de la Vulgata. Nada podía estar más alejado de esa Enlightenment Bible, que como ha apuntado Jonathan Sheehan «was, by nature, never singular, always plural» ${ }^{43}$, que el llamamiento cursado por Scio en uno de los paratextos de la segunda edición de su traducción para convertirla en la Biblia de la nación española en cuanto nación católica. El sexto parágrafo de la segunda de las disertaciones que la preludiaban se dedicaba específicamente a probar que «en una nación católica parece más conveniente que haya una sola versión literal de las escrituras en su respectivo idioma» ${ }^{44}$.

Poco importa además que ese anhelo de Scio no se vería estrictamente cumplido. Cuando en I823 Torres Amat consumaba la apropiación del manuscrito de Petisco que conocía y poseía en cuanto integrante de la junta de censores que en I805 había evaluado -y desestimado- su posible edición, la nación católica pasaba ciertamente a tener dos posibilidades de lectura de la Biblia en castellano. Salvo en el plano estilístico, no había sin embargo diferencias mayores entre ellas. Obedecían a la misma lógica de control de la autoridad de las sagradas escrituras y a la misma

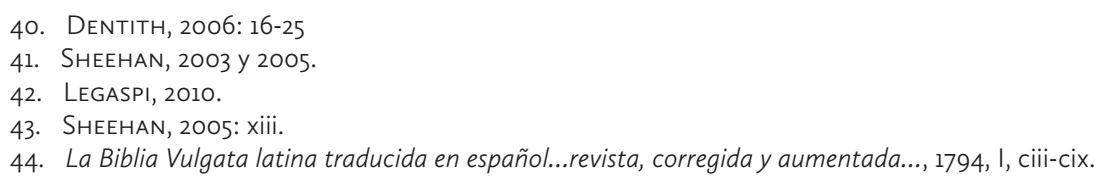


voluntad de preservarlas como escrituras de autoridad. En última instancia, en ninguno de ambos casos se trasgredía la frontera y demarcación de traducibilidad trazada por el Diccionario de Armesto y Goyanes al problematizar y estigmatizar como intraducible incluso la vía católica de relación con la erudición y la crítica que podía representar Calmet. Para que la misma llegara a tener espacio y recorrido en la traducción bíblica al castellano habría de hecho de consumarse una crisis imperial. Y no sería significativamente en la península donde prendiese una iniciativa de ese signo, sino en la naciente república mejicana, donde en i83I el impresor y traductor Marino Galván Rivera iniciaría la publicación de la traducción por él coordinada de la conocida como Biblia de Vence en la versión fijada por Laurent Etienne Rondet. Concretamente, de la cuarta edición, impresa en París en I820, de La Sainte Bible en latin et en français : avec des notes littérales, critiques et historiques : des préfaces et des dissertations tirées du Commentaire de Augustin Calmet, Abbé de Senones, de l'Abbé de Vence, et des auteurs les plus célèbres : pour faciliter l'intelligence de l'Écriture Sainte: ouvrage enrichi de cartes géographiques et de figures ${ }^{45}$.

6.- Un año después, en I832, Martínez Marina incorporaba en su Historia un balance personal y nada complaciente de toda esa secuencia de traducción bíblica al castellano. En su opinión, y anotando la sensibilidad hacia la lengua que le guiaba, el saldo que arrojaba el reciente ciclo de traducción de la Biblia resultaba llanamente frustrante. No sólo estaba lejos de haber dado a la imprenta alguna traducción que pudiera siquiera acercarse a la de Alfonso X, por la que confesaba su absoluta preferencia y predilección. Al lamento motivado porque «esta versión permanezca sepultada en un desierto y en las sombras del olvido, sin que se haya hecho uso de ella en las traslaciones castellanas publicadas en nuestros días», seguía la referencia a las «célebres traducciones de Casiodoro de Reina y de Cipriano de Valera», que se ensalzaban también como «más exactas que las modernas» ${ }^{46}$.

Martínez Marina no era el primero que entonces invocaba esas traducciones cuyo sesgo confesional precisamente había precipitado la promulgación del decreto inquisitorial que prohibía la lectura y traducción de la Biblia al vernáculo desde I559 en el ámbito monárquico, un lustro antes de la adopción de esa misma lógica para el conjunto del universo católico, no sin controversia, en la regla IV del Index tridentino ${ }^{47}$. Su citación y reseña constituía por el contrario una parte nuclear del discurso de quienes al menos desde mediados del Setecientos con más empeño habían defendido la restitución de esa lectura y traducción vernácula alegando una memoria y tradición cultural propia. Reina y Valera comparecían con la misma naturalidad en las páginas del Ensayo de una biblioteca de traductores de Pellicer y Saforcada, o en las de la Biblioteca española de Rodríguez de Castro, que en los

45. Sagrada Biblia en latín y español con notas literales, críticas é históricas, prefacios y disertaciones, sacadas del comentario de D. Agustin Calmet, abad de Senones, del abad Vencé y de los mas célebres autores, para facilitar la inteligencia de la Santa Escritura, Méjico, 1831.

46. Martínez Marina, 1832: 13-15.

47. Agten, 2018: 93-110. Fragnito, 1997 
prólogos de Scio y Amat ${ }^{48}$. Lo que sin embargo diferenciaba a Martínez Marina de todos ellos eran los términos en los que planteaba esa invocación. Por un lado, porque entendía como una estrategia errónea el haberse embarcado en unas nuevas iniciativas de traducción omitiéndose la posibilidad de recuperar y reeditar, con la oportuna incorporación de unas «correcciones» confesionales, aquellas obras que con «loable economía» brindaban «todo lo que se necesita para leer con provecho las sagradas escrituras». Y por otro, dando una mayor hondura a su desafecto, porque tampoco titubeaba al precisar que el motivo por el que entendía que los trabajos de Reina o Valera resultaban superiores residía en que habían operado «sobre el texto original hebreo y griego».

Ya no se trataba por tanto de cuestionar tan sólo las concretas realizaciones de unos traductores modernos, su pericia y sus decisiones, sino que así iba más lejos y procedía a problematizar los propios supuestos y prescripciones sobre los que se había venido a articular la recuperación de la política de la traducción bíblica al vernáculo en el espacio católico. Ahora bien, que a partir de esa posición pudiera estar modulándose una vía de incorporación de los supuestos de la crítica bíblica era algo que ni siquiera se insinuaba en ese discurso preliminar de la Historia. Al revés. La mera añoranza de unas ediciones bíblicas del Quinientos de hecho ya suponía, con independencia de su controvertida implicación confesional, la adopción de un referente anterior al tiempo en el que todo había cambiado en materia de crítica bíblica. Desde las páginas de su Bibliotheque choisi, en I703, y en reseña de una obra propia, Le nouveau testament de Notre Seigneur Jesus-Christ traduit sur l'original Grec (Lorme, Amsterdam, I703), una voz tan autorizada como la de Jean Le Clerc había sentenciado con rotundidad que sólo era «depuis le commencement du XVIl siecle» cuando se habían forjado «plus de lumieres \& de secours que l'on avoit jamais auparavant», y con ello, «les regles de la plus exacte \& de la plus fine Critique» interesada en «l'Ecriture Sainte» ${ }^{49}$.

Cierto es que en su encumbramiento como «constitución de los cristianos» Martínez Marina podía decir que aún «prescindiendo de su origen celestial y de su sagrada y canónica autoridad», esto es, que aún «considerado como cualquier otro libro histórico y examinado por las reglas y principios de la más severa crítica», el evangelio era «incomparablemente superior y aventaja a todos los escritos humanos» ${ }^{50}$. Buena parte del discurso se dedicaba justamente a respaldar esa afirmación y a desacreditar el empleo de las «reglas de la crítica» por los «historiadores filósofos» que «exagerando» las «luces y sagrados derechos de la razón» habían procedido a cuestionar el estilo y la veracidad de los textos y el «método que siguieron los evangelistas» ${ }^{5 \mathrm{I}}$. Pero ello no significaba, ni mucho menos, que Martínez Marina estuviera además dispuesto a prescindir de la defensa y reivindicación de aquel «origen celestial» $\mathrm{y}$ «divinidad de los libros santos». Tampoco la referencia al evangelio como «esta obra sublime que aun considerada

\footnotetext{
48. Pellicer y Saforcada: 1778: 31-39 y 41-45. Rodríguez de Castro, 1781: 464-471.

49. Le Clerc, 1703: II, 269.

50. Martínez Marina, 1832: 21-22.

51. Martínez Marina, 1832: 23, 26-27.
} 
como meramente humana es la flor de la razón más ilustrada y el compendio de la más pura y santa filosofía», había conducido a Jovellanos al cuestionamiento de su carácter revelado ${ }^{52}$. Y lo mismo sucedía con Martínez Marina, que incluso daba un paso más y convertía su Historia en la solemne convocatoria de un combate contra los «extremados censores del evangelio» que aferrados al instrumental filológico no reconocían en su letra ni siquiera «vestigios de la intervención de la divinidad»"33.

No era una tarea a la que además se aplicase con ligereza. Quizás porque tenía la perspicacia y el conocimiento preciso para detectar dónde se situaba el verdadero epicentro del debate: en el lenguaje. De ahí que el nervio argumental sobre el que se articulaba el Discurso se centrase en clarificar que la afirmación de la «divinidad de las escrituras» no implicaba «creer que Dios ha revelado inmediatamente a los evangelistas todo lo que han escrito, hasta la gramática y los vocablos». Interesaba además a Martínez Marina no sólo insistir y remarcar que «el idioma, la gramática y el orden» de los libros bíblicos era «obra de los escritores» y que «el divino espíritu autor de los libros sagrados se acomodó al genio, carácter, lengua y estilo de aquellos hombres que había escogido como instrumentos para comunicar sus oráculos y dar a conocer su voluntad». Con idéntico empeño procedía a enfatizar que «los evangelistas, dirigidos por el espíritu que los animaba, procuraron acomodar su historia a las necesidades de la iglesia y de los fieles»; esto es, que «sus escritos son análogos a las circunstancias en que se hallaban», y que en ello radicaba la causa de «la gran diferencia que se advierte en el lenguaje de los profetas entre el evangelio de San Juan y el de los otros evangelistas, o entre las epístolas de San Pablo y los escritos de los demás apóstoles» ${ }^{54}$. Se tejía de este modo toda una urdimbre llamada a neutralizar el planteamiento de quienes en la estela de Jean Le Clerc, en nombre de la inestabilidad e imperfección de las lenguas, circunscribían el entendimiento de la revelación a la serie de encuentros directos de Jesucristo con los apóstoles originales diferenciando los evangelios de Lucas y Mateo, que se habrían limitado a relatar lo que habían visto y oído hacer y decir a Jesús, y aquellos otros como el de San Juan que incorporaban ya una actividad de la mente tan central en la cultura helenística como era la filosofía. A partir de esa distinción, en la que el evangelio de Juan o la epístola de San Pablo a los Corintios devenían en sofisticados artefactos filosóficos que se encomendaban a la metafísica griega para explicar el Dios que habían conocido, era como se había consumado la sustitución de la teología por una historia del lenguaje $\mathrm{e}^{55}$.

Impedir que esa sustitución pudiera prender en el ámbito católico era la causa que movilizaba e inducía a Martínez Marina a conjurar los cantos de sirena que entendía entonados por unos deístas y que llamaban a asumir «que nuestras lenguas son obra de los hombres y los hombres son limitados». Era la estrategia natural para quien vislumbraba que el antídoto frente al despliegue crítico que tantas dudas había terminado proyectando sobre la inspiración divina de las escrituras no pasaba por

52. JOVELLANOS, 2010: 390.

53. Martínez Marina, 1832: 45-47.

54. Martínez Marina, 1832: 41 y $47-48$.

55. POCOCK, 2008: 86-89. 
defender sino por renunciar a sostener que el «divino espíritu» hubiera «dictado palabra por palabra todo lo que escribieron y hablaron, no solamente la doctrina, los dogmas, los hechos, y las relaciones históricas, sino también las sentencias, las frases, las expresiones, el lenguaje, el estilo los términos y hasta la ortografía, vírgulas, ápices, puntos y comas». Lo mismo y en los mismos términos que sucedía en materia de estilo, donde en opinión de Martínez Marina la batalla no había de orientarse a comparar si la Biblia se «levanta en hermosura, elocuencia y elegancia sobre los de Jenofonte, Livio, Salustio y otros que no fueron inspirados», sino a descartar que tuviera operatividad y sentido el que unos «evangelios destinados a instruir a todos los hombres, en todos los siglos y en todas las naciones, fuesen obras consumadas, piezas selectas de erudición y elocuencia» ${ }^{56}$. La cuestión, venía así a decretar Martínez Marina reduciendo a cenizas la más honda sustancia de la crítica bíblica, no era de lengua, como tampoco lo era de estilo, sino de fe: «nosotros creemos la divinidad de las escrituras no por el carácter peculiar que representan sus escritores, ni por la elegancia y sublimidad del estilo, sino por la excelencia de la doctrina y porque nos anuncia constantemente la verdad, porque Dios ha excitado a los autores a escribir por un impulso sobrenatural de su gracia». Ese era el caso y el asunto, el de una «sabiduría increada» cuyo conocimiento resultaba inaccesible a las «investigaciones humanas» ${ }^{57}$.

7.- Centrarse en la lengua no suponía que Martínez Marina desatendiera además otros frentes de la controversia bíblica, comenzando por la reivindicación del estatus y soberanía de la tradición en la custodia del sentido y los dogmas de las escrituras. Con un vocabulario en el que resonaban con fuerza los ecos de la retórica, no de Richard Simon, sino prcisamente la de Bossuet, el Discurso dedicaba un espacio a la identificación de las «variaciones de las iglesias protestantes» como la evidencia que acreditaba tanto la improcedencia de la doctrina de la sola escritura como la trascendencia de la tradición en la comprensión de los textos bíblicos. No empleaba además medias tintas al definir a la iglesia como «tribunal establecido por Jesucristo para determinar el verdadero sentido de las escrituras santas», por mucho que en buena parte de sus obras el propio Martínez Marina tampoco hubiese dejado de visualizar el despotismo papal como un ídolo que necesariamente había de derribarse $^{58}$. Ambos registros podían compatibilizarse con naturalidad, tal y como lo había puesto de manifiesto algo antes, hacía I818, al componer una Defensa contra las censuras inquisitoriales recibidas por su Teoría de las Cortes y su Ensayo histórico crítico sobre la antigua legislación de España.

En uno de los epígrafes de esa Defensa procedía a ajustar cuentas con la imputación de haber poblado aquel par de textos de ciertas «proposiciones contrarias a la doctrina de los Santos Padres», y más concretamente, irreconciliables con el dictado de San Jerónimo, San Agustín y San Juan Crisostomo ${ }^{59}$. Y lo hacía

\footnotetext{
56. Martínez Marina, 1832: 42-46.

57. Martínez Marina, 1832: 48.

58. Martínez Marina, 1832: 55-58.

59. Martínez Marina, 1861: 145-158
} 
distinguiendo las materias de religión y moral, en las que «cualquier proposición contraria al común sentir de los santos doctores» se hacía acreedora de la «más severa censura teológica», de unos alternativos «asuntos», que resultaban ser los de «critica, historia, filosofía y política», y en los que cuando no había acuerdo en el dictamen patrístico no cabía reproche por tomar partido en alguno de los sentidos posibles. Esa distinción resultaba sumamente operativa para fundamentar los dos niveles argumentales en los que disponía su Defensa: en primera instancia, permitía precisar que los fragmentos de sus obras sobre los que los censores habían cargado las tintas no guardaban relación con el dogma o la doctrina cristiana, sino que estaban dedicados, sin excepción, a la consideración problemática de los bienes eclesiásticos, y ante todo de los diezmos; y en segundo lugar, sin por ello dejar de cuestionar que Jerónimo, Agustín y Crisóstomo hubieran además hablado de los diezmos «en sentido riguroso, legal y canónico», la distinción posibilitaba incidir en que al emitir su censura los censores habían omitido la diversidad de posiciones que entre «los santos padres» se habían suscitado con ese concreto motivo. No obstante, más allá de la especificidad del caso que daba pie a su precisión, esa diferenciación iluminaba bien una posición de fondo respecto a la actividad crítica, delimitando el perímetro en el que había de contenerse y negando cualquier forma de incursión de la misma en los dominios del dogma y la doctrina o cualquier vía de erosión en la comprensión de la centralidad de la tradición: «los escritos de tan insignes varones», escribía Martínez Marina para evitar equívocos, «son el canal de la tradición, y la conformidad de sus doctrinas y sentimientos en materia de religión y moral cristiana constituye uno de los principales argumentos o lugares teológicos para probar los dogmas $»^{60}$.

Era una forma indirecta pero sumamente elocuente de establecer además que la ausencia de cualquier porosidad hacia la crítica de los textos bíblicos y postbíblicos no tenía por qué conllevar una unanimidad en el terreno de la forma ecclesiae. Como por extenso venía a hacerlo notar luego la Historia, la aspiración de una comunidad cristiana sin lectores de Simon y Le Clerc, y de la que fueran desterrados cualquiera de los linajes intelectuales que estos habían inaugurando, resultaba doblemente invariable: era un principio estable de la economía cultural tanto de la monarquía católica anterior a I8I2 como de la nación también católica a la que entonces daba paso; y era a su vez un elemento común y compartido tanto por quienes detestaban como por quienes anhelaban la fusión entre republicanismo clásico y cristianismo virtuoso al modo de Martínez Marina. Es más, llevando el cierre frente a la crítica bíblica hasta su último extremo era él quien incluso consideraba inconvenientes las operaciones de traducción como la de las Vindicias de la sagrada escritura de Du-Clot (I825), por el efecto indirecto de difusión que podía llegar a tener la obligada consideración de los críticos que descalificaba. Y en ese sentido puede por tanto decirse que, al igual que en otras vertientes habitualmente ensombrecidas por la hondura de su reflexión jurídico-política, como pudiera ser según se ha recordado recientemente su personal teorización sobre la necesidad de una constitución de la

6o. Martínez Marina, 1861: 145-146. 
lengua previa a la imaginación de una constitución política ${ }^{61}$, tampoco en la esfera del criticismo bíblico la entidad de su pensamiento resulta insignificante. Más bien al contrario, pues su Historia sólo puede ser leída como testimonio de la radicalidad con la que incluso desde la complicidad con un horizonte de religión civil se pudo asumir entonces el reto de la preservación de la Biblia como un espacio intelectual inaccesible para la crítica.

61. Fernández Albaladejo, 2021. 


\section{BIBLIOGRAFÍA}

Agten, Els, «Las traducciones de la Biblia al castellano y la Reforma», en Michel Boeglin, Ignasi Fernández Terricabras y David Kahn (eds.), Reforma y disidencia religiosa. La recepción de las doctrinas reformadas en la península ibérica en el siglo XVI, Madrid, Casa de Velázquez, 2018: 93-IIo.

Apocalypsis del Apostol San Juan traducido al castellano según la Vulgata con las anotaciones históricas, dogmáticas y morales que trae en su versión Don Antonio Pereira de Figueiredo, Diputado en Lisboa de la Real Mesa Censoria, por D. José de Palacio y Viana, Madrid, Isidoro Hernández Pacheco, I789.

Armesto y Goyanes, José, Diccionario histórico, cronológico, geográfico y universal de la Santa Biblia, Madrid, Oficina de Blas Román, I788-I793.

Bernier, Jean, «Le probléme de la tradition chez Richard Simon et Jean Le Clrec», Revue des sciences religieuses, 82/2 (2008): 199-223.

Bernier, Jean, La critique du Pentateuque de Hobbes à Calmet, Paris, Honoré Champion, 2 oro.

Bordoli, Roberto, L'Illuminismo di Dio: alle origini della mentalit 'a liberale. Religione, teologia, filosofia e storia in Johann Salomo Semler (I725-I79I), Torino, L. S. Olschki, 2004.

Bossuet, Jacques-Benigne Defensa de la tradición y de los Santos Padres, Madrid, Imprenta de Blas Román, I778a.

Bossuet, Jacques-Benigne, Discurso sobre la Historia Universal, Madrid, Andrés Ortega, I778b.

Calmet, Agustim, Historia del Antiguo y nuevo Testamento y de los judíos, para servir de introducción a la Historia Eclesiástica de M. el Abad Fleury, traduzida al español por Fr. Miguel Martínez de Virgala, Madrid, Imprenta de Benito Cano, I789.

Dentith, Simon, «Homer, Ossian and Modernity», Epic and Empire in Nineteenth-Century Britain, Cambridge, Cambridge U.P., 2006.

EgIDo, Teófanes, «Religión», en Francisco Aguilar Piñal (ed.): Historia literaria de España en el siglo XVIII, Madrid, Trotta, I996: 739-8I4

Fernandez Albaladejo, Pablo, «El cristianismo cívico de Francisco Martínez Marina», en Materia de España. Cultura política e identidad en la España moderna, Madrid, Marcial Pons, 2007: 323-350.

Fernandez Albaladejo, Pablo, «Fábulas de origen y gramática de nación en la España del siglo XVIIl. A propósito de algunos trabajos de Francisco Martínez Marina», en Espacio, Tiempo y Forma. Serie IV, 34 (202I): 4I7-440.

Fragnito, Gigliola, La Bibbia al rogo: La censura ecclesiastica e i volgarizzamenti della Scrittura, I47I-I605, Bologna, Il Mulino, I997.

Grossı, Paolo, Mitología jurídica de la modernidad, Madrid, Marcial Pons, $200 \mathrm{I}$

GusDorf, Gorges, Les origines de l'herméneutique, Paris, Les Éditions Payot, I988.

Hardy, Nicholas, Criticism and Confession. The Bible in the Seventeenth Century Republic of Letters, Oxford, Oxford U.P., 2017.

Jovellanos, Gaspar Melchor de, La primera fuente de prosperidad es la instrucción, en Olegario Negrín-Fajardo (ed.), Obras Completas, XIII, Escritos Pedagógicos, Gijón, Instituto Feijoo de Estudios del Siglo XVIII, 2 oro.

Koselleck, Reinhart, Crítica y crisis. Un estudio sobre la patogénesis del mundo burgués, Madrid, Trotta, 2007.

LAmbe, Patrick J., «Biblical criticism and censorship in Ancien Régime France: The case of Richard Simon», Harvard Theological Review, 78/I-2 (I985): I49-I77. 
LAPLANChe, François, La Bible en France entre mythe et critique, XVIe-XIXe siècle, París, Albin Michel, 1994.

Le BRUn, Jacques, «L'antiaugustinisme de Richard Simon», Revue de l'histoire des religions, 229/ 2 (2012): 257-273.

LE CLERC, Jean, Bibliotheque choisie, pour servir de suite a la Bibliotheque Universelle, Amsterdam, Henry Schelte, I703.

LegasPI, Michael C., The death of scripture and the rise of biblical studies, Oxford, Oxford U.P., 2010.

León, Fray Luis de, Exposición del Libro de Job, Madrid, Pedro Marín, I779.

Malcolm, Noel, «Hobbes, Ezra, and the Bible: The History of a Subversive Idea», en Aspects of Hobbes, Oxford, Oxford U.P., 2002: 383-430.

MALlET, Edme-François y Diderot, Denis, «Bible», en Encyclopédie ou Dictionnaire raisonné des sciences, des arts et des métiers, París, I75I, 2: 222-227

Martínez Marina, Francisco, Historia de la Vida de Nuestro Señor Jesucristo y de la doctrina y moral cristiana, Zaragoza, Librerías de Gallifa y de Polo y Monge Hermanos, I832.

Martínez Marina, Francisco, Defensa del Doctor Don Francisco Martínez Marina contra las censuras dadas por el tribunal de la Inquisición a dos de sus obras: Teoría de las Cortes y Ensayo histórico-crítico sobre la antigua legislación de España, Imprenta de Francisco Sánchez, Madrid, I86I.

Mestre, Antonio, Influjo europeo y herencia hispánica. Mayans y la ilustración valenciana, Valencia, Ayuntamiento de Oliva, 1987.

Momigliano, Arnaldo, The Classical Foundations of Modern Historiography, Berkeley, University of California Press, I990.

Morrow, Jeffrey L. Three Skeptics and the Bible: La Peyrère, Hobbes, Spinoza, and the Reception of Modern Biblical Criticism, Pickwick, Eugene, 2016.

Pitassi, Maria Cristina, Entre croire et savoir: Le probléme de la methode critique chez Jean Le Clerc, Leiden, E. J. Brill, I987.

Pellicer y SAforcada, Jun Antonio, Ensayo de una Bibliotheca de traductores españoles, donde se da noticia de las traducciones que hay en castellano de la Sagrada Escritura, Santos Padres, Filósofos, Historiadores, Médicos, Oradores, poetas, así griegos como latinos, y de otros autores que han florecido antes de la invención de la imprenta, Madrid, Antonio de Sancha, I778.

Petite, Anselmo, Los Santos Evangelios traducidos al castellano con notas sacadas de los Santos Padres y Expositores Sagrados, Valladolid, Tomás de Santander, I785.

PORTILlo, José María, Revolución de nación. Orígenes de la cultura constitucional en España, I780-I8I2, Centro de Estudios Políticos y Constitucionales, Madrid, 2000.

PоткAY, Adam, «Virtue and Manners in Macpherson's Poems of Ossian», Publications of the Modern Language Association of America, I07/I (1992): I20-30.

Pососк, John G.A., «Historiography and Enlightenment: A view of their history», Modern Intellectual History, 5/I(2008): 83-96.

Poсоск, John G.A., Barbarism and Religion. Vol. 5, Religion: The First Triumph, Cambridge, Cambridge U.P., 2010.

PopkIn, Richard H., «Spinoza and Bible scholarship», en Don Garrett (ed.), The Cambridge companion to Spinoza, Cambridge, Cambridge U.P., I986:383-407.

Rodríguez DE CASTRO, José, Biblioteca española. Tomo primero, que contiene la noticia de los escritores rabinos españoles desde la época conocida de su literatura hasta el presente, Madrid, Imprenta Real de la Gazeta, I78I.

Rossi, Paolo, I Segni del tempo. Storia della Terra e storia delle nazioni da Hooke a Vico, Milán, Feltrinelli, 2003. 
Sagrada Biblia en latín y español con notas literales, críticas é históricas, prefacios y disertaciones, sacadas del comentario de D. Agustin Calmet, abad de Senones, del abad Vencé y de los mas célebres autores, para facilitar la inteligencia de la Santa Escritura, Méjico, I83I.

SÁnchez CARO, José Manuel, Biblia e Ilustración: versiones castellanas de la Biblia en el Siglo de las Luces, Vigo, Academia del Hispanismo, 2012.

SÁnChez León, Pablo, «Ordenar la civilización: semántica del concepto de policía en la Ilustración española», Política y sociedad, 42/3 (2005): 139-I56.

Scio de SAn Miguel, Phelippe, La Biblia Vulgata latina traducida en español y anotada conforme al sentido de los Santos Padres y expositores católicos por Phelippe Scio de San Miguel, Valencia, Oficina de Joseph y Thomas de Orga, I790-93.

Scio de SAn Miguel, Phelippe, La Biblia Vulgata latina traducida en español y anotada conforme al sentido de los Santos Padres y expositores católicos por Phelippe Scio de San Miguel, revista, corregida y aumentada por su mismo traductor, Madrid, Imprenta de Don Benito Cano, I794

SHEEHAN, Jonathan, «From Philology to Fossils: The Biblical Encyclopedia in Early Modern Europe», Journal of the History of Ideas, 64/I (2003): 4I-60.

Sheenan, Jonathan, The Enlightenment Bible. Translation, Scholarship, Culture, Princeton U.P., Princeton, 2005.

Terreros y Pando, Esteban de, Diccionario castellano con las voces de ciencias y artes y sus correspondientes en las tres lenguas, francesa, latina e italiana, Madrid, Imprenta de la Viuda de Ibarra e Hijos, I786.

Torres Amat, Félix, La Sagrada Biblia nuevamente traducida de la Vulgata latina al español, aclarado el sentido de algunos lugares con la luz que dan los textos originales hebreo y griego, e ilustrada con varias notas sacadas de los Santos Padres y expositores sagrados, por Félix Torres Amat, Madrid, Imprenta de Don Amarita, 1823-25.

Twining, Timothy «Richard Simon and the Remaking of Seventeenth-Century Biblical Criticism», Erudition and the Republic of Letters, 3/4 (2018): 42I-487.

Villanueva, Joaquín Lorenzo, De la lección de las sagradas escrituras en lenguas vulgares, Valencia, Benito Monfort, I79I.

Westler, Brendon, «Between Tradition and Revolution: The Curious Case of Francisco Martínez Marina, the Cadiz Constitution, and Spanish Liberalism», Journal of the History of ideas, 76/3 (2015): 394-4I6. 



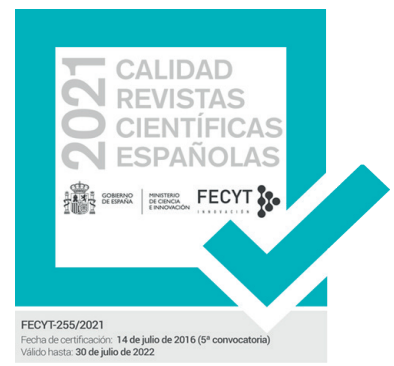

SERIE IV HISTORIA MODERNA

REVISTA DE LA FACULTAD DE GEOGRAFÍA E HISTORIA

AÑO 2021

ISSN: 1131-768X

E-ISSN 2340-1400

\section{4 \\ 西 ESPACIO, TIEMPO Y FORMA}

Monográfico - Special Issue: La política ultramarina de las monarquías ibéricas (circa 1700-1750): una historia de fracasos y éxitos relativos The Overseas Policy of the Iberian Monarchies (Circa 1700-1750): A History of Failures and Relative Successes

15 Roberto Quirós Rosado y MARIA FERnANDA BICALHO La política ultramarina de las monarquías ibéricas (circa 1700-1750): una historia de fracasos y éxitos relativos / The Overseas Policy of the Iberian Monarchies (Circa 1700-1750): A History of Failures and Relative Successes

\section{Guillaume Hanotin}

Defender negocios en tiempo de convulsión política: las elites mercantiles francesas durante la guerra de Sucesión española / Protecting Business in Time of Crisis: French Trademen during the War of Spanish Succession

\subsection{Maria Fernanda Bicalmo}

Ultramarino y el auge de los secretarios de Estado en Portugal durante la primera mitad del siglo XVIII / Sobre este modo de resolver e despachar os negócios. The decline of the Overseas Council and the Rise of the Secretaries of State in Portugal during the First Half of the $18^{\text {th }}$ Century

\section{9}

\section{VALENTINA FAVARò}

El fracaso de los proyectos de reforma en el virreinato peruano de principios

del siglo XVIII. Las propuestas de Carmine Nicola Caracciolo, príncipe de Santobuono the Eighteenth Century. The Proposals of Carmine Nicola Caracciolo, Prince of Santobuono

\section{7}

\section{ROBERTO QUIRÓS ROSADO}

Ecos de un mercantilismo truncado. El conde de Pinos Puente y la diplomacia comercial de Carlos VI en la corte de Lisboa (1723-1724) / Echoes of a Failed Mercantilism. The Count of Pinos Puente and the Commercial Diplomacy of Charles VI at the Court Of Lisbon (1723-1724)

\section{Junia Ferreira Furtado}

Portuguese America under Foreign Threat and the Creation of the Concept of uti possidetis in the First Half of the $18^{\text {th }}$ Century / La américa portuguesa bajo la amenaza exterior y la creación del concepto de uti possidetis en la primera mitad del siglo XVIII

\section{Miscelánea $\cdot$ Miscellany}

\section{José Antonio Mateos Royo}

con Cataluña / Trade Policy and Monetary Circulation in Aragon: Conflicts and Agreements with Catalonia (1535-1565)

\section{Fernando Altoé}

panegíricos atribuidos a la impresion. Un estudio de la trayectoria de dos the Trajectory of Two Panegyrics Attributed to João de Barros

\section{Francisco Velasco Hernández}

reino de Murcia (siglos XVI y XVII) / The Influence of the Berber Corsican on the Late Repopulation on the Coastal Area on the Kingdom of Murcia (XVI and XVII Centuries)

\section{José Antonio Martínez Martínez}

Criados, jornaleros y esclavos al servicio de la familia: la servidumbre de Serfdom of the Muñoz de Otálora in the $17^{\text {th }}$ Century

\section{Víctor Daniel Regalado González-Serna}

Benito de Medina a raíz de su ingreso en el cabildo catedral de Sevilla en 1669 / «Not a Single Good Portuguese». Accusations against Priest Alonso Benito de Medina when Entering the Cathedral Chapter of Seville in 1669

\section{José Herrera Reviriego}

organigrama comercial y militar de la Gober a tólo mitad del siglo XVII / "Only Time will Tell us»: The Role of Taiwan within the Commercial and Military Organization of the Philippine's Governoration during the First Half of the Seventeenth Century

\section{Manuel-Reyes García Hurtado}

de Rande, 1719-1733 / Vicissitudes of the Rescue Companies of the Sunken Ships in the Battle of Rande, 1719-1733

\subsection{Marcos de Miguel Muñoz}

Caballeros in 1769 


\section{4 ESPACIO, TIEMPO Y FORMA}

\section{Javier Tinoco Domínguez}

Tensiones sociopolíticas en el marco del catastro de Ensenada en Jerez de la Frontera: estudio de un conflicto institucional / Socio-Political Tensions within the Framework of Cadastre of Ensenada In Jerez de la Frontera: A Studying of an Institucional Conflict

\section{Pablo Fernández Albaladejo}

Fábulas de origen y gramática de nación en la España del siglo XVIII. A propósito de algunos trabajos de Francisco Martínez Marina / Origin's Fables and Grammar of Nation in the XVIII Century Spain. About some Works by Francisco Martínez Marina

\subsection{José María IÑURRITEgui Rodríguez}

Constitución increada: Francisco Martínez Marina y la crítica bíblica / Uncreated Constitution. Francisco Martínez Marina and Biblical Criticism

\subsection{David A. Abián Cubillo}

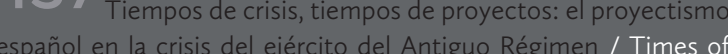
crisis, Times of Projects: The Spanish proyectismo during the Army's Crisis in the Ancient Regime

Taller de historiografía · Historiography Workshop

\section{Ensayos · Essays}

\subsection{ChrISTOPH ROSENMÜLLER}

«Tan peligrosas y feas conspiraciones»: la relación escrita por el embajador austriaco Christoph Migazzi en 1754 sobre la caída del marqués de la Ensenada / «Dangerous and Ugly Conspiracies». The Report of the Austrian Ambassador Christoph Migazzi on the Fall of the Marquis of la Ensenada in 1754

\subsection{Serge Gruzinskı}

Quelle histoire enseigner en 2021 ? / ¿Qué historia enseñar en 2021?

\subsection{Carlos Amate Pizarro}

Las relaciones hispano-chinas en el siglo XVI: síntesis e interpretación a la luz de la reciente historiografía / The Hispanic-chinese Relationship in the XVI Century: Synthesis and Interpretation in the Light of Recent Historiography

\section{Reseñas • Book Review}

521 Bolufer Peruga, Mónica, Arte y artificio de la vida en común. Los modelos de comportamiento y sus tensiones en el Siglo de las Luces, (Julio ArRoyo Vozmediano) 


\section{4 ESPACIO, TIEMPO Y FORMA}

525 Melón, Amando, Alejandro de Humboldt. Vida y obra (Carlos Martínez Shaw)

52 Commentary to Tatiana Seijas' review of The Atlantic World and the Manila Galleons: Circulation, Market, and Consumption of Asian Goods in the Spanish Empire (JosÉ LuIs GASCH TOMAS)

533 Braguier, Laurey, Servantes de dieu. Les beatas de la Couronne de Castille (1450-1600) (Manuela Águeda GARCÍA-GARRIDO)

539 Romeo, María CRuz; SAlomón, María Pilar; TABANERA, Nuria (eds.): Católicos, Reaccionarios y Nacionalistas. Política e identidad nacional en Europa y América Latina Contemporáneas (JAVIER M. Dos SANTOS)

54 Heredia López, Alfonso Jesús, El control de la corrupción en la Monarquía Hispánica. La Casa de la Contratación (1642-1660) (José Manuel Díaz Blanco)

17 Andújar Castillo, Francisco, El Atila de Madrid. La forja de un banquero en la crisis de la monarquía (1685-1715) (Aitor Díaz PAREdes)

551 Serrano Aviles, Javier y Mojarro, Jorge (eds.) Prada GonzALEZ, María (coord. de ilustraciones), En el archipiélago de la Especiería. España y Molucas en los siglos XVI y XVII (İ̃̃ıGo VALPUESTA VILLA)

555 Díaz Ceballos, Jorge, Poder compartido. Repúblicas urbanas, Monarquía y conversación en Castilla del Oro, 1508-1573 (JUAN SEbAstián Gómez GonZÁleZ)

51 Edelmayer, Friedrich, Massimiliano II, Filippo II I'Italia imperiale. II marchesato di Finale, i diritti imperiali e il «camino spagnolo» (RAFAEL VALLADARES)

56 Escribano-PÁEZ, José M., Juan Rena and the Frontiers of Spanish Empire, 1500-1540 (DAvid Martín Marcos)

56 ARnOLD, David, La Era de los Descubrimientos (1400-1600), Madrid, Alianza Editorial, 2021, 184 Pp., ISBN: 978-841362-172-2 (CARlos Amate Pizarro) 